\title{
Ancient diversification of eukaryotic MCM DNA replication
} proteins

\author{
Yuan Liu ${ }^{1}$, Thomas A Richards ${ }^{1}$ and Stephen J Aves*2
}

Address: ${ }^{1}$ Centre for Eukaryotic Evolutionary Microbiology, School of Biosciences, University of Exeter, Geoffrey Pope Building, Stocker Road, Exeter, EX4 4QD, UK and ${ }^{2}$ School of Biosciences, University of Exeter, Geoffrey Pope Building, Stocker Road, Exeter, EX4 4QD, UK

Email: Yuan Liu - yl274@exeter.ac.uk; Thomas A Richards - t.a.richards@exeter.ac.uk; Stephen J Aves* - s.j.aves@exeter.ac.uk

* Corresponding author

Published: 17 March 2009

BMC Evolutionary Biology 2009, 9:60 doi:10.1 |86/|47|-2|48-9-60

This article is available from: http://www.biomedcentral.com/I47I-2/48/9/60

(c) 2009 Liu et al; licensee BioMed Central Ltd.

This is an Open Access article distributed under the terms of the Creative Commons Attribution License (http://creativecommons.org/licenses/by/2.0), which permits unrestricted use, distribution, and reproduction in any medium, provided the original work is properly cited.
Received: 29 September 2008

Accepted: 17 March 2009

\begin{abstract}
Background: Yeast and animal cells require six mini-chromosome maintenance proteins (Mcm27) for pre-replication complex formation, DNA replication initiation and DNA synthesis. These six individual MCM proteins form distinct heterogeneous subunits within a hexamer which is believed to form the replicative helicase and which associates with the essential but non-homologous Mcm 10 protein during DNA replication. In contrast Archaea generally only possess one MCM homologue which forms a homohexameric MCM helicase. In some eukaryotes $\mathrm{Mcm} 8$ and Mcm9 paralogues also appear to be involved in DNA replication although their exact roles are unclear.
\end{abstract}

Results: We used comparative genomics and phylogenetics to reconstruct the diversification of the eukaryotic Mcm2-9 gene family, demonstrating that Mcm2-9 were formed by seven gene duplication events before the last common ancestor of the eukaryotes. Mcm2-7 protein paralogues were present in all eukaryote genomes studied suggesting that no gene loss or functional replacements have been tolerated during the evolutionary diversification of eukaryotes. $M \mathrm{~cm} 8$ and 9 are widely distributed in eukaryotes and group together on the MCM phylogenetic tree to the exclusion of all other MCM paralogues suggesting co-ancestry. Mcm8 and Mcm9 are absent in some taxa, including Trichomonas and Giardia, and appear to have been secondarily lost in some fungi and some animals. The presence and absence of $\mathrm{Mcm} 8$ and 9 is concordant in all taxa sampled with the exception of Drosophila species. Mcm IO is present in most eukaryotes sampled but shows no concordant pattern of presence or absence with Mcm8 or 9.

Conclusion: A multifaceted and heterogeneous Mcm2-7 hexamer evolved during the early evolution of the eukaryote cell in parallel with numerous other acquisitions in cell complexity and prior to the diversification of extant eukaryotes. The conservation of all six paralogues throughout the eukaryotes suggests that each Mcm2-7 hexamer component has an exclusive functional role, either by a combination of unique lock and key interactions between MCM hexamer subunits and/ or by a range of novel side interactions. Mcm8 and 9 evolved early in eukaryote cell evolution and their pattern of presence or absence suggests that they may have linked functions. Mcm8 is highly divergent in all Drosophila species and may not provide a good model for Mcm8 in other eukaryotes. 


\section{Background}

DNA replication in eukaryotes is catalysed by a complex of proteins termed the replisome. Formation of the replisome occurs at multiple origins of replication and is a stepwise process co-ordinated by the cell cycle control machinery (reviewed in [1]). Central to the replisome in all phases of its genesis and function are MCM (minichromosome maintenance) proteins.

The genes encoding MCM proteins were first identified in budding and fission yeasts through various cell cycle mutant screens, most notably Bik Tye's $\mathrm{mcm}$ screen for mutants of Saccharomyces cerevisiae defective in the ability to propagate centromeric plasmids containing a single origin of replication [2]. The phenotype of many $\mathrm{mcm}$ mutants is dependent on the exact identity of the origin of replication, suggesting a defect affecting the initiation of DNA replication [3]. In $S$. cerevisiae six MCM genes, MCM2-MCM7 [4], were originally identified and have shared sequence characteristics suggesting homology and a history of paralogous duplication [5].

The MCM proteins form numerous and complex interactions, central to which is the formation of a hexamer, the Mcm2-7 complex [5,6]. Mcm2-7 is loaded on to the origin recognition complex (ORC) at the origin of replication prior to DNA replication, during late $M$ and G1 phases of the cell cycle, to form the pre-replication complex (pre$\mathrm{RC}$ ). This is activated at the G1-S transition of the cell cycle by the assembly of further protein components, including the non-homologous $\mathrm{Mcm} 10$ protein, in response to cell cycle kinase activities (reviewed in [7]). Mcm10 associates with the Mcm2-7 hexamer in the active replisome and helps to stabilise DNA polymerase $\alpha$-primase (reviewed in [8]). Mcm2-7, together with other accessory factors, is believed to act as the replicative helicase, unwinding DNA at the two replication forks to provide single-stranded template on which replicative synthesis can take place $[9,10]$.

Genes encoding MCM helicases are also found in Archaea (although not in Eubacteria currently sampled) but, in contrast to eukaryotes, the archaeal helicase generally comprises a homohexamer formed from multiple protein copies encoded by a single MCM gene [11]. Mcm10 has no recognised homologue in Archaea. Two more members of the Mcm2-7 family have recently been described in eukaryotes: Mcm8 and Mcm9. Mcm8 functions in aspects of DNA replication in vertebrates [12-15] but not in Drosophila, where it has a meiotic role $[16,17]$; it is absent from nematodes and yeast. Less is known about $\mathrm{Mcm} 9$ [18] which is the largest of the Mcm2-9 paralogues, having a unique long C-terminal region [19]. It was originally thought that $\mathrm{Mcm} 9$ is vertebrate-specific as it is absent from Drosophila, nematodes and yeasts [19], but it is now recognised that $\mathrm{Mcm} 8$ and $M \mathrm{~cm} 9$ have a more widespread eukaryotic distribution $[17,20,21]$. Mcm 1 is a transcription factor which is not directly involved in DNA replication and will not be considered here $[22,23]$.

Our knowledge of MCM proteins and DNA replication is derived from research principally based on yeast and vertebrate animals. These taxa are members of the opisthokonts, which according to current taxonomic consensus is one of six eukaryotic 'supergroups' [24] and therefore only represents a relative small proportion of the evolutionary history and genomic diversity of known eukaryotic life. For the other five eukaryotic supergroups, studies of the DNA replisome or MCM protein function and diversity are limited [25]. Here we use comparative genomics and phylogenetic analysis to investigate the distribution of MCM DNA replication proteins across the eukaryotes, to reconstruct the evolutionary history of the Mcm2-9 proteins, and to gain insights into MCM functional diversification, in distantly related eukaryotic taxa and at the base of the eukaryotic tree of life.

\section{Results and discussion Identification of MCMs}

BLAST algorithms were used to identify MCM homologues encoded by the eukaryotic genomes of the 37 species listed in Table 1, covering five of the six eukaryotic supergroups [24,26-28] (Rhizaria unsampled). In Naegleria and Xenopus there were two proteins that grouped with Mcm3, and in Xenopus two Mcm6 proteins were found [29], providing the only examples of recent MCM duplication events among the taxa investigated. Comparative genomics and phylogenetic analysis (Fig. 1) showed that genes encoding six MCM proteins, Mcm2-7 homologues, were present in every eukaryotic genome sampled. These data suggest that the last common eukaryotic ancestor (LCEA) possessed all six $\mathrm{Mcm} 2-7$ paralogues and this ancient cell was therefore likely to contain a multi-subunit MCM protein complex composed of six paralogous proteins. These data suggest that an intricate and heterogeneous MCM protein complex evolved in an early phase of eukaryotic evolution.

Genes encoding the two most recently identified MCM family proteins, $\mathrm{Mcm} 8$ and $\mathrm{Mcm}$ 9, were found to be present in the majority of eukaryotic genomes analysed and only absent in some opisthokonts, excavates and chromalveolates. Generally the $\mathrm{Mcm} 8$ and $\mathrm{Mcm} 9$ paralogues were either both present or both absent, suggesting that $\mathrm{Mcm} 8$ and $\mathrm{Mcm} 9$ may have associated functions. Of the taxa surveyed we found only one exception to this rule: Drosophila spp. possess $\mathrm{Mcm} 8$ but lack $\mathrm{Mcm}$ 9.

BLAST searches and local Pfam searches of Mcm10 homologues showed that Mcm 10 was also widely distributed 
A

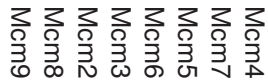

Amoebozoa $1000100 \begin{aligned} & \text { Dictyostelium discoideum * } \\ & \text { Entamoeba histolytica* }\end{aligned}$
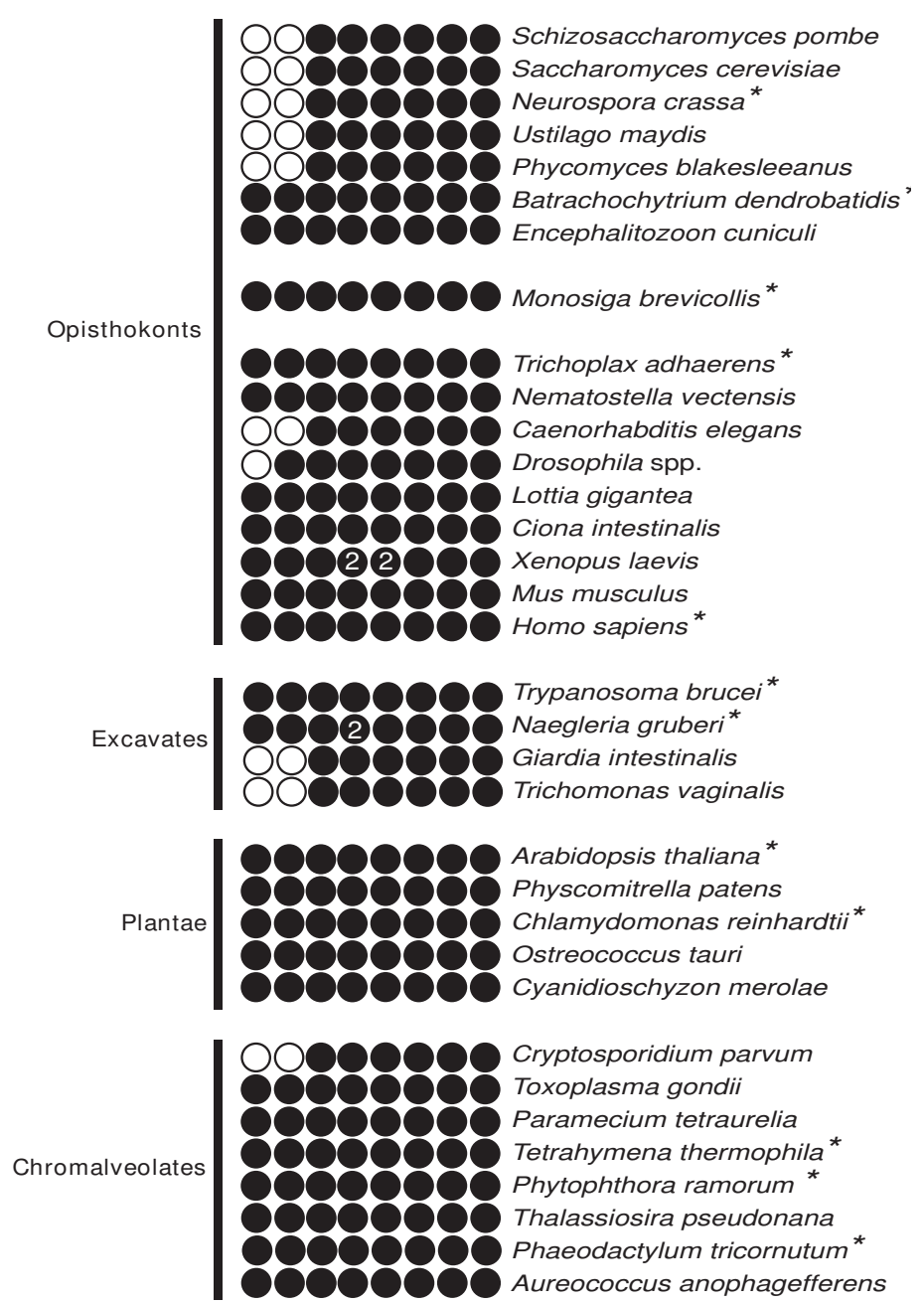

B

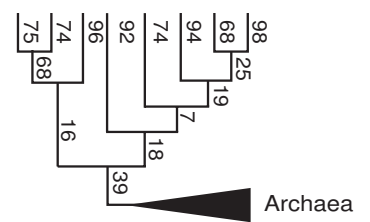

Figure I

Taxonomic distribution of Mcm2-9 and a summarised phylogenetic tree of MCMs. This analysis shows that Mcm29 are present in the majority of the major eukaryotic 'supergroups' and that each MCM forms a moderate to strongly supported monophyletic group. Together these data demonstrate that $\mathrm{Mcm} 2-9$ were present in the last common eukaryotic ancestor. (A) Comparative genomic survey of MCM paralogues in 37 eukaryotic taxa. Mcm2-9 are shown on the x-axis and taxa are shown on the $y$-axis. Black circles indicate detections and open circles indicate no orthologues detected. Numbers within the black circles indicate the number of that specific MCM paralogue found in the taxa. Asterisks indicate species used for the "Noah's Ark" subset: for the results of the phylogenetic analysis see Additional file 5. (B) A summarised phylogenetic tree of MCMs based on Additional files I, 2, 3, 4, emphasising the ML bootstrap support values for each MCM family, and relationships between each family which in most cases are weakly supported. The Archaea were used as an outgroup for reconstructing MCM phylogeny. 
among the eukaryotes sampled (Table 1). Mcm10 is conserved in opisthokonts and Plantae, except in Encephalitozoon and Cyanidioschyzon which represent eukaryotes with relatively small genomes and often encode divergent protein sequences $[30,31]$. Mcm 10 proteins exhibit greater sequence divergence than $\mathrm{Mcm} 2-9$ orthologues and we cannot rule out that some $\mathrm{Mcm} 10$ orthologues may have fallen below detection limits employed here, however the distribution pattern of $\mathrm{Mcm} 10$ in representatives of different eukaryotic supergroups does not correlate with that of Mcm8 and Mcm9 (Table 1).

\section{The phylogeny and evolution of eukaryotic Mcm2-9}

A phylogeny of the full Mcm2-9 protein family was reconstructed from the amino acid alignments of each conserved MCM domain [5,32] by performing a fast Maximum-likelihood (ML) analysis using PHYML [33] and a Bayesian analysis using MRBAYES [34]. Both phylogenetic analyses classified the MCM homologues as belonging to specific paralogue families and resolved the eukaryotic Mcm2-7 paralogues into six distinct monophyletic groups (Additional files 1, 2, 3, 4). Each MCM paralogous set was supported by moderate to high ML bootstrap values and Bayesian posterior probabilities (Mcm2: 96\%/1.00 respectively; $\mathrm{Mcm} 3$ : 92\%/1.00; $\mathrm{Mcm} 4$ : 98\%/1.00; Mcm5: 94\%/1.00; Mcm6: 74\%/1.00; Mcm7: 68\%/1.00) (Fig. 1B and Additional files 1, 2, 3). These results support the conclusion that all six $\mathrm{Mcm} 2-7$ proteins were present in the LCEA and that consecutive duplication, which formed these six defined MCM paralogues, occurred prior to the diversification of the sampled eukaryotic taxa.

Our phylogenetic analyses also grouped $\mathrm{Mcm} 8$ and $\mathrm{Mcm} 9$ into two distinct monophyletic groups supported by ML bootstrap values and Bayesian posterior probabilities (Mcm8: 74\%/1.00; Mcm9: 75\%/0.99) and placed Mcm8 and $\mathrm{Mcm} 9$ as sister paralogues to the exclusion of all other MCM paralogues (68\% ML bootstrap support) (Fig. 1B and Additional file 4). This shared derived ancestry and linked pattern of presence and absence suggest that $\mathrm{Mcm} 8$ and $\mathrm{Mcm} 9$ have both co-function and distinct co-ancestry.

Both phylogenetic analyses failed to resolve the branching relationship between the MCM paralogues. To attempt to resolve these relationships a "Noah's Ark" dataset was analysed comprising a more limited sampling of eukaryotes from each major taxon (species indicated by asterisks in Fig 1); this also failed to yield resolution in the backbone of the tree (Additional file 5). The lack of resolution among these ancient paralogue groups may be the consequence of lack of signal within the relatively short alignment used for phylogenetic analyses (240 amino acid characters). This feature could also be a product of a hard polytomy or the rapid consecutive duplication of MCM parental forms into eight paralogues at the base of the eukaryotic tree resulting in limited availability of evolutionary signal to support the relative branching order of the MCM paralogues.

Previous studies on DNA replication of Archaea have already shown that the core replication machineries of the eukaryotes and Archaea possess fundamental similarities and have many homologous protein components [35], indicative of common ancestry. There is currently no known eubacterial homologue to the eukaryotic MCMs but we identified a single highly conserved MCM homologue in all the Archaea studied (except Methanococcus jannaschii which possesses four MCM proteins). Our phylogenetic analyses demonstrated that the four paralogues in the complete genome sequence of the euryarchaeote M. jannaschii can be best explained by a series of Archaea-specific gene duplications (98\% ML bootstrap support) (Additional file 4) which occurred separately from the eukaryotic MCM gene duplications. Our analyses therefore suggest that the eukaryotic Mcm2-9 may be derived by gene duplication events from a single, archaeal-like, ancestral MCM and the diversification of this archaeal-like MCM would have given rise to $\mathrm{Mcm}$ 2-9 encoded in the genome of the LCEA.

\section{The phylogeny and evolution of Drosophila Mcm8}

Drosophila melanogaster was the only species sampled that did not show co-possession or co-absence of $\mathrm{Mcm} 8$ and Mcm9. Our general MCM phylogeny suggested that the $D$. melanogaster Mcm8 protein was highly divergent (Additional file 4). To further investigate the apparent loss of $\mathrm{Mcm} 9$ and radical divergence of Mcm8 in Drosophila species we conducted an animal Mcm8 and 9 phylogenetic analysis which included a sampling of all 12 Drosophila genomes and additional Insecta genome sequences, plus additional outgroups. The Mcm8 and Mcm9 comparative genomic analyses and phylogeny demonstrated the monophyletic groupings of $\mathrm{Mcm} 8$ and $\mathrm{Mcm} 9$ and confirmed the absence of Mcm9 in all the Drosophila species (100\% ML bootstrap support and 1.00 Bayesian posterior probability; Fig. 2). This analysis also demonstrated that the Drosophila Mcm8 cluster formed an extremely long branch within the animal Mcm 8 clade (100\% ML bootstrap support and 1.00 Bayesian posterior probability; Fig. 2) suggesting a pattern of radical evolutionary change specifically in the Drosophila Mcm8 gene family. The divergence of Drosophila Mcm8 from other Mcm8 sequences may be related to the absence of Mcm9 in Drosophila or a radical change in functional role.

\section{Gain and loss of Mcm8 and Mcm9 in eukaryotic evolution} The comparative genomics studies of MCMs have revealed that $\mathrm{Mcm} 8$ and $\mathrm{Mcm} 9$ are widely distributed in (at least) 
Table I: Taxonomic distribution of Mcm I 0 in eukaryotes.

\begin{tabular}{|c|c|c|c|c|c|}
\hline Supergroup & Rank & Species & Mcm IO & Mcm8 & Mcm9 \\
\hline \multirow[t]{2}{*}{ Amoebozoa } & Dictyostelids & $\begin{array}{l}\text { Dictyostelium } \\
\text { discoideum }\end{array}$ & - & + & + \\
\hline & Archamoebae & $\begin{array}{l}\text { Entamoeba } \\
\text { histolytica }\end{array}$ & - & + & + \\
\hline \multirow[t]{8}{*}{ Chromalveolates } & Phaeophytes & $\begin{array}{l}\text { Aureococcus } \\
\text { anophagefferens }\end{array}$ & - & + & + \\
\hline & Ciliates & $\begin{array}{l}\text { Paramecium } \\
\text { tetraurelia }\end{array}$ & - & + & + \\
\hline & & $\begin{array}{l}\text { Tetrahymena } \\
\text { thermophila }\end{array}$ & - & + & + \\
\hline & Apicomplexa & $\begin{array}{l}\text { Cryptosporidium } \\
\text { parvum }\end{array}$ & - & - & - \\
\hline & & $\begin{array}{l}\text { Toxoplasma } \\
\text { gondii }\end{array}$ & $\begin{array}{l}55 . \mathrm{m} 04882 \\
\text { (ToxoDB) }\end{array}$ & + & + \\
\hline & Oomycetes & $\begin{array}{l}\text { Phytophthora } \\
\text { ramorum }\end{array}$ & $\begin{array}{l}\text { Phyra I_I:82084 } \\
\text { (JGI) }\end{array}$ & + & + \\
\hline & Diatoms & $\begin{array}{l}\text { Phaeodactylum } \\
\text { tricornutum }\end{array}$ & $\begin{array}{l}\text { Phatr2:32848 } \\
\text { (JGI) }\end{array}$ & + & + \\
\hline & & $\begin{array}{l}\text { Thalassiosira } \\
\text { pseudonana }\end{array}$ & $\begin{array}{l}\text { Thaps3:7942 } \\
\text { (JGI) }\end{array}$ & + & + \\
\hline \multirow[t]{4}{*}{ Excavates } & Heterolobosea & $\begin{array}{l}\text { Naegleria } \\
\text { gruberi }\end{array}$ & - & + & + \\
\hline & Diplomonads & $\begin{array}{l}\text { Giardia } \\
\text { lamblia }\end{array}$ & - & - & - \\
\hline & Parabasalids & $\begin{array}{l}\text { Trichomonas } \\
\text { vaginalis }\end{array}$ & $X P \_001314784$ & - & - \\
\hline & Kinetoplastids & $\begin{array}{l}\text { Trypanosoma } \\
\text { brucei }\end{array}$ & XP_803462 & + & + \\
\hline \multirow[t]{5}{*}{ Plantae } & Land Plants & $\begin{array}{l}\text { Arabidopsis } \\
\text { thaliana }\end{array}$ & NP_I79694 & + & + \\
\hline & & $\begin{array}{l}\text { Physcomitrella } \\
\text { patens }\end{array}$ & $\begin{array}{l}\text { Phypal_I:I83570 } \\
\text { (JGI) }\end{array}$ & + & + \\
\hline & Chlorophytes & $\begin{array}{l}\text { Chlamydomonas } \\
\text { reinhardtii }\end{array}$ & NP_00I692606 & + & + \\
\hline & & $\begin{array}{l}\text { Ostreococcus } \\
\text { tauri }\end{array}$ & $\begin{array}{l}\text { Ostta4:34955 } \\
\text { (JGI) }\end{array}$ & + & + \\
\hline & Red Algae & $\begin{array}{l}\text { Cyanidioschyzon } \\
\text { merolae }\end{array}$ & - & + & + \\
\hline
\end{tabular}


Table I: Taxonomic distribution of Mcm 10 in eukaryotes. (Continued)

\begin{tabular}{|c|c|c|c|c|c|}
\hline \multirow{10}{*}{\multicolumn{2}{|c|}{ Opisthokonts }} & $\begin{array}{l}\text { Caenorhabditis } \\
\text { elegans }\end{array}$ & NP_499456 & - & - \\
\hline & & $\begin{array}{l}\text { Ciona } \\
\text { intestinalis }\end{array}$ & $\begin{array}{l}\text { Cioin2:216242 } \\
\text { (JGI) }\end{array}$ & + & + \\
\hline & & $\begin{array}{l}\text { Drosophila } \\
\text { melanogaster }\end{array}$ & NP_610097 & + & - \\
\hline & & $\begin{array}{l}\text { Mus } \\
\text { musculus }\end{array}$ & NP_08I566 & + & + \\
\hline & & $\begin{array}{l}\text { Nematostella } \\
\text { vectensis }\end{array}$ & XP_00I624863 & - & - \\
\hline & & $\begin{array}{l}\text { Homo } \\
\text { sapiens }\end{array}$ & NP_877428* & + & + \\
\hline & & & NP_060988* & & \\
\hline & & $\begin{array}{l}\text { Lottia } \\
\text { gigantea }\end{array}$ & $\begin{array}{l}\text { Lotgil:238353 } \\
\text { (JGI) }\end{array}$ & + & + \\
\hline & & $\begin{array}{l}\text { Trichoplax } \\
\text { adhaerens }\end{array}$ & $\begin{array}{l}\text { Triadl:5539I } \\
\text { (JGI) }\end{array}$ & + & + \\
\hline & & $\begin{array}{l}\text { Xenopus } \\
\text { laevis }\end{array}$ & NP_00I082048 & + & + \\
\hline \multirow{7}{*}{\multicolumn{2}{|c|}{ Fungi }} & $\begin{array}{l}\text { Batrachochytrium } \\
\text { dendrobatidis }\end{array}$ & $\begin{array}{l}\text { BDEG_01898 } \\
\text { (BROAD) }\end{array}$ & + & + \\
\hline & & $\begin{array}{l}\text { Encephalitozoon } \\
\text { cuniculi }\end{array}$ & - & + & + \\
\hline & & $\begin{array}{l}\text { Neurospora } \\
\text { crassa }\end{array}$ & XP_960373 & - & - \\
\hline & & $\begin{array}{l}\text { Saccharomyces } \\
\text { cerevisiae }\end{array}$ & NP_012116 & - & - \\
\hline & & $\begin{array}{l}\text { Schizosaccharomyces } \\
\text { pombe }\end{array}$ & NP_596702 & - & - \\
\hline & & $\begin{array}{l}\text { Phycomyces } \\
\text { blakesleeanus }\end{array}$ & $\begin{array}{l}\text { Phybll:72484 } \\
\text { (JGI) }\end{array}$ & - & - \\
\hline & & $\begin{array}{l}\text { Ustilago } \\
\text { maydis }\end{array}$ & XP_7585I5 & - & - \\
\hline & Choanoflagellates & $\begin{array}{l}\text { Monosiga } \\
\text { brevicollis }\end{array}$ & $\begin{array}{l}\text { Monbr I:32446 } \\
\text { (JGI) }\end{array}$ & + & + \\
\hline
\end{tabular}

"+" indicates presence of an orthologue. "-" indicates that no orthologue was detected in the genome. "*" indicates that the genome encodes two isoforms of Mcm 10.

five of the six eukaryotic supergroups and only absent in some opisthokonts, excavates and chromalveolates. By adapting current understandings on the phylogenetic and taxonomic groupings of the eukaryotes $[26-28,36]$ it is possible to make some deductions about gain and loss events of $\mathrm{Mcm} 8$ and $\mathrm{Mcm} 9$ across the eukaryotic evolutionary tree. The presence of $\mathrm{Mcm} 8$ and $\mathrm{Mcm} 9$ in five of the six supergroups suggests that $\mathrm{Mcm} 8$ and $\mathrm{Mcm} 9$ also 
arose early in eukaryotic evolution. Mcm8 and $\mathrm{Mcm} 9$ were both absent from all analysed fungal genomes, with the exception of Encephalitozoon and Batrachochytrium. In comparison to the current consensus fungal phylogeny $[37,38]$, these data suggest that the loss of $\mathrm{Mcm} 8$ and 9 in the fungi was probably a shared loss event in the last common ancestor of the ascomycetes, basidiomycetes and zygomycetes sampled. Further secondary loss events were identified in the Apicomplexa Cryptosporidium and in the animal Caenorhabditis lineages.

Mcm8 and 9 were absent in the excavates Giardia and Trichomonas which according to some schemes for the eukaryotic phylogeny are potentially the primary branch in the eukaryotic phylogeny [39]. Since the root of the eukaryotic tree is still unclear, when the Mcm8 and Mcm9 paralogues originated within the eukaryotic phylogeny remains a puzzle. However, a homologue of Mcm8 was detected as a partial sequence in Genome Survey Sequences (GSS) data for the diplomonad Spironucleus barkhanus, which is a close relative of Giardia. This suggests that $\mathrm{Mcm} 8$ and possibly $\mathrm{Mcm} 9$ originated before the common ancestor of Giardia and Trichomonas branched from the base of the eukaryotic tree and that Mcm8 and Mcm9 were also present in the LCEA. This identifies at least two additional cases of $\mathrm{Mcm} 8-9$ co-loss within the 'metamonads' [40,41] including one loss in the diplomonads (Giardia) and the parabasalids (Trichomonas).

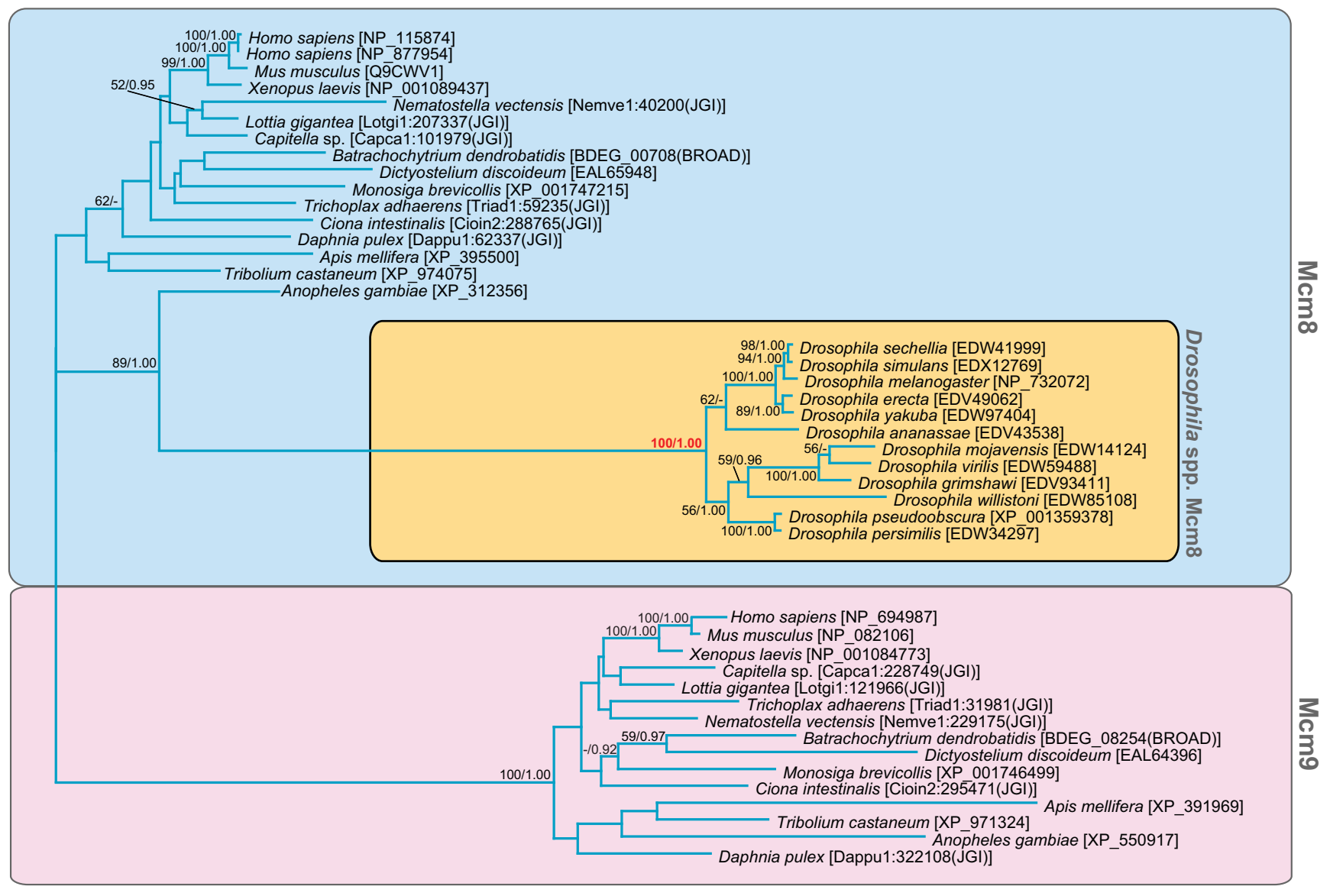

$\longmapsto 0.1$ subs/site

\section{Figure 2}

Phylogenetic analysis of animal $\mathbf{M c m 8}$ and $\mathbf{M c m} 9$. This analysis was conducted to investigate the diversification and branching position of the Drosophila $\mathrm{Mcm} 8$ proteins as Drosophila is the only lineage with an Mcm8 but with no Mcm9. The analysis shows that the Drosophila Mcm8 proteins are highly divergent. The phylogeny shown is a calculated from an amino acid alignment of 43 sequences and 366 characters. The tree topology shown was calculated using PHYML methods. Mcm8 paralogues are shown in blue and $\mathrm{Mcm} 9$ paralogues in pink. The orange coloured block indicates the relationship of Drosophila spp. Mcm8 with Mcm8 sequences from other animals plus additional outgroups. Numbers on nodes indicate the ML bootstraps and Bayesian posterior probabilities (bootstrap values below $50 \%$ and posterior probabilities below 0.90 are not shown). The phylogeny is shown as rooted on the Mcm9 paralogue. 
Together this suggests at least five separate cases of paired Mcm8 and 9 loss during the eukaryotic radiation, providing indirect support for the hypothesis that Mcm8 and 9 may have some currently unidentified interdependent functional roles.

\section{Reciprocity between MCM evolution and function studies} In most Archaea, a single MCM forms a homohexamer. A number of archaeal MCMs have been demonstrated to act as a helicase to unwind double-stranded DNA [35]. Helicase activity of eukaryotic MCMs has been found in vitro in a sub-complex of Mcm4, Mcm6 and Mcm7 [42] or in a super-complex of Mcm2-7 with Cdc45 and GINS accessory proteins $[9,10]$. The comparative genomics and phylogenetic analysis of MCMs have revealed that the LCEA possessed all six Mcm2-7 proteins, which seem to have diversified from a single archaeal-like, ancestral MCM. This suggests that the ancestral enzymatic activity of eukaryotic Mcm2-7 proteins is unwinding DNA as a processive helicase. Because both eukaryotes and Archaea have a functional complex of six individual MCMs it is likely that early eukaryotes also had a six-protein MCM functional complex. However, eukaryotes replaced a single gene six-protein complex with a six gene six-protein complex.

Mcm8 and Mcm9 have received relatively few functional studies. Mcm8 has been characterised recently in humans, Xenopus and Drosophila $[12-17,43]$. Human and Xenopus Mcm8 function in DNA replication, although there is no consensus regarding their exact role(s); early evidence suggested this may be in the elongation phase of DNA replication $[12,13]$, but human Mcm 8 has also been shown to associate and co-localise with $\mathrm{Cdc} 6$, an Mcm2-7 loading factor, implying a role in pre-RC formation [14,15]. The early evolutionary acquisitions of $\mathrm{Mcm} 8$ and $\mathrm{Mcm} 9$ suggest that Mcm 8 in other eukaryotes might also have similar roles. The putative co-function of $\mathrm{Mcm} 8$ and $\mathrm{Mcm} 9$ as demonstrated by the pattern of co-presence, co-loss and distinct co-ancestry suggests that $\mathrm{Mcm} 9$ is also involved in DNA replication; this is supported by the recent demonstration that that Xenopus Mcm9 acts as a positive regulator of the Mcm2-7 loading factor Cdt 1 and is required for assembly of pre-replication complexes [44]. Future comparative studies on $\mathrm{Mcm} 8$ and 9 functions will be informative.

In addition, a role in meiotic recombination has been identified for the Drosophila Mcm8, REC [16,17]. Drosophila was the only eukaryote analysed which has $\mathrm{Mcm} 8$ but lacks Mcm9 suggesting, if the co-function and distinct co-ancestry hypothesis is correct, that REC may have assumed the function of both proteins or acquired a novel function that does not require Mcm9 specifically in Drosophila. Mcm8 and Mcm9 are therefore likely to co-func- tion in meiotic recombination in other eukaryotic lineages, but further work is required to investigate this hypothesis. The loss of $\mathrm{Mcm} 8$ and $\mathrm{Mcm} 9$ in some opisthokont lineages and Cryptosporidium could mean that $\mathrm{Mcm} 8$ and $\mathrm{Mcm} 9$ are dispensable for meiotic recombination or other unknown functions. Comparative genomics analyses of meiotic genes indicate that Giardia possesses several protein components required for meiosis $[45,46]$. Further studies should attempt to investigate and compare meiosis and $\mathrm{Mcm} 8$ and $\mathrm{Mcm} 9$ function between Giardia and other eukaryotes capable of sexual reproduction and which encode $\mathrm{Mcm} 8$ and $\mathrm{Mcm}$ 9.

Functional studies on $\mathrm{Mcm} 10$ proteins suggest that $\mathrm{Mcm} 10$ is required for both DNA initiation and elongation phase of DNA replication [8]. In yeast and Xenopus, Mcm10 binds to both chromatin and the Mcm2-7 complex and recruits Cdc45 and DNA polymerase $\alpha$-primase to replication origins [47-50]. Mcm10 forms part of the replisome complex that migrates away from replication origins during S-phase $[50,51]$ and is required for stability and activity of the initiating polymerase, DNA polymerase $\alpha$-primase [50,52]. Mcm10 homologues were found neither in Archaea nor in Eubacteria; the appearance of this protein seems to be unique within eukaryotes. The evolutionary pattern of Mcm 10 (Table 1) indicates the importance and functional similarities of Mcm 10 homologues within the eukaryotic genomes analysed.

\section{Conclusion}

We have carried out a broad and deep phylogenetic analysis of MCM proteins involved in DNA replication. Eukaryote genomes encode up to nine such proteins all of which have an ancient origin and diversification within the eukaryotic lineage. Subunits of the Mcm2-7 hexamer appear to be universally present in eukaryotic taxa, as predicted by their likely DNA helicase role in DNA replication. Mcm2-9 distribution demonstrates diversification by gene duplication prior to the LCEA of extant eukaryotic supergroups. Mcm8 and 9 paralogues exhibit a distribution pattern characteristic of interdependent loss events in some taxa. Co-loss suggests related functions for $\mathrm{Mcm} 8$ and 9, which may play more peripheral roles in the cell than Mcm2-7. Finally, the non-homologous Mcm10 protein appears to be exclusively eukaryotic and exhibits greater sequence divergence across taxa than the $M \mathrm{~cm} 2-9$ family.

\section{Methods \\ Sequence Data}

We compared the DNA scaffold predicted transcriptome, and the annotated protein databases of 37 complete or draft eukaryotic genome sequence databases listed in Additional file 6 . 
In addition to the predicted eukaryotic protein databases, predicted protein databases of Archaea Sulfolobus acidocaldarius, Thermofilum pendens, Methanococcus jannaschii, Archaeoglobus fulgidus, Thermoplasma volcanium, Pyrococcus horikoshii, Nanoarchaeum equitans and Halobacterium sp. were also sampled to use as outgroups for the phylogenetic analyses. Archaeal genomes were available from the National Center for Biotechnology Information (NCBI) http://www.ncbi.nlm.nih.gov/. To further confirm that no MCM homologues were detected in eubacterial genomes we also performed 'eubacterial'-restricted tBLASTn, BLASTp and PSI-BLAST searches of GenBank non-redundant sequence databases.

\section{Identifying Mcm2-7, Mcm8 and Mcm9 homologues}

Homologous sequences of $\mathrm{Mcm} 2$ to $\mathrm{Mcm} 7$ proteins were identified by performing an all-against-all search of eukaryotic (listed in Additional file 6) and archaeal protein databases using the BLASTp algorithm with a cutoff expectation (E) value of $1 \times 10^{-20}$. Candidates were tested by reciprocal BLAST searches. Mcm8 and Mcm9 homologues were checked by using both BLASTp and tBLASTn searches in BLAST options of the respective genome projects (listed in Additional file 6), with putative $\mathrm{Mcm} 8$ and $\mathrm{Mcm} 9$ protein sequences of closely related taxa as a BLAST seed for these sub-analyses. These multiple BLAST searches using paralogous genes as search seeds were conducted to ensure that all available paralogues were sampled from each of the target genomes. In cases of apparent absence, EST and GSS data of closely-related species were also searched. All candidate MCM proteins were checked by performing an NCBI Conserved Domain Database (CDD) search to confirm that all amino acid sequences sampled possessed an MCM domain. This analytical process recovered a number of protein sequences that were annotated as putative $\mathrm{Mcm} 2-7$ but were potentially misclassified paralogues. We therefore based our paralogue designation on phylogenetic analyses reported below.

\section{Identifying Mcm I 0 homologues}

A search for $\mathrm{Mcm} 10$ homologues was performed with BLASTp and tBLASTn. The E-value of $1 \times 10^{-4}$ was used as cutoff to define $\mathrm{Mcm} 10$ homologous proteins. PSI-BLAST searches and local Pfam searches of eukaryotic databases were performed in order to identify more divergent $\mathrm{Mcm} 10$ homologues. PSI-BLAST searches were terminated after three iterations and revealed putative Naegleria $\mathrm{Mcm} 10$ (E-value $=3 \times 10^{-9}$ in PSI-BLAST iteration 2), Trichomonas $\mathrm{Mcm} 10$ (E-value $=1 \times 10^{-6}$ in PSI-BLAST iteration 2) and Chlamydomonas Mcm10 (E-value $=1 \times 10^{-37}$ in PSI-BLAST iteration 3), expanding the taxonomic distribution and evolutionary history of the $\mathrm{Mcm} 10$ protein family. Local Pfam searches were performed using the Hidden Markov Model (HMM) profile of $\mathrm{Mcm} 10$ domain available from Pfam (PF09332) [53] using the program
HMMER http://hmmer.janelia.org/; no further potential Mcm10 homologues were detected.

\section{Eukaryotic Mcm2-9 phylogeny}

The 290 putative MCM protein sequences were extracted and aligned using the multiple sequence alignment program MUSCLE [54] using the default settings. Putative Ostreococcus Mcm7 and Aureococcus Mcm8 had partial or comparatively 'noisy' sequences so were excluded from the analysis. The hypothetical Plasmodium berghei MCM genes were excluded because they were highly divergent and the sequences could not be aligned with confidence for the phylogenetic analysis. This process produced a multiple amino acid sequence alignment of 280 sequences which was manually corrected and then masked using the alignment editor SEAVIEW [55]. We masked the alignment prior to phylogenetic analyses to remove noisy or gappy regions and to focus the character sampling on the conserved MCM box region [5,32]. Xenopus zygotic Mcm3 [GenBank:Q7ZXZ0] and zygotic Mcm6 [GenBank:NP 001080590] were removed as they differed by only few amino acid residues from maternal $\mathrm{Mcm} 3$ and $\mathrm{Mcm} 6$ respectively after masking. This process produced an alignment of 278 sequences and 240 amino acid characters for phylogenetic analysis. Because of the size of this dataset we found that we could not execute the MODELGENERATOR [56] program even using relatively powerful computer platforms. Fast ML analyses were performed using the software PHYML with the WAG substitution matrix and the proportion of invariable sites (I) and eight category gamma distribution $(\Gamma)$ estimated by PHYML [33]. 100 bootstrap replicates were calculated using PHYML to test topological support. To test alternative substitution matrices we repeated the analysis using the recently-developed LG matrix [57] which has been reported as an improvement on the WAG matrix. This analysis gave a similar result with slightly reduced bootstrap support values for the monophyly of the MCM paralogues (Additional file 7). Bayesian analysis was performed using MRBAYES [34], using the WAG substitution matrix as for the fast ML analysis. MRBAYES was run with two sets of four simultaneous Markov chains with a default temperature string and for 2 million generations and trees were sampled every 100 generations. The log likelihood output was compared across both runs and a burn-in of 5000 generation samples was excluded and a consensus phylogeny calculated from the remaining samples. The outputs of all analyses were viewed by the software TREEVIEW [58]. A "Noah's Ark" dataset was also analysed which comprised 14 eukaryotes (indicated by asterisks in Fig 1) sampled from each major taxon and included 120 sequences and an alignment sampling of 307 amino acid characters. MODELGENERATOR identified RtREV $+\Gamma$ as the most appropriate substitution matrix with eight discrete categories and estimated the gamma 
distribution $(\Gamma)$ parameter $\alpha$ as 0.49 .100 bootstrap replicates were calculated using PHYML.

\section{Animal Mcm8 and Mcm9 phylogeny}

The general eukaryotic analyses demonstrate a potentially complicated pattern of gene loss for $\mathrm{Mcm} 8$ and $\mathrm{Mcm} 9$ across the animals. Homologues of Capitella sp., Ciona intestinalis, Daphnia pulex, Tribolium castaneum, Anopheles gambiae, Apis mellifera, Mus musculus, Homo sapiens, Xenopus laevis, Lottia gigantea, Nematostella vectensis, Trichoplax adhaerens (representing a wide taxonomic span of animals) and 12 Drosophila species were sampled and used for an additional animal-specific $\mathrm{Mcm} 8$ and $\mathrm{Mcm} 9$ phylogenetic analysis including 43 sequences and an alignment sampling of 366 amino acid characters. Amoebozoa Dictyostelium, the fungus Batrachochytrium and the choanoflagellate Monosiga $\mathrm{Mcm} 8$ and $\mathrm{Mcm} 9$ were included as outgroup taxa. This animal-specific $\mathrm{Mcm} 8$ and $\mathrm{Mcm} 9$ phylogeny was analysed using the same procedure as before. MODELGENERATOR identified $R t R E V+\Gamma$ as the most appropriate model with eight discrete categories and estimated the $\Gamma$ parameter $\alpha$ as 0.93 . Bootstrap analysis was carried out with 500 replicates. For the Bayesian analysis, we also analysed the Mcm8 and 9 phylogeny using MRBAYES with an RtREV $+\Gamma$ model of sequence substitution. The Bayesian analysis was run as above but for one million generations with the first 400 generation samples discarded as burn-in. Both results were displayed using TREEVIEW.

\section{Authors' contributions}

SJA and TAR conceived and planned the project. TAR designed the phylogenetic analysis. All authors contributed to design of bioinformatic analyses which were carried out by YL with supervision from TAR and SJA. All authors discussed the results, drafted and approved the final manuscript.

\section{Additional material}

\section{Additional file 1}

Phylogenetic analysis of eukaryotic Mcm2-9 (part 1: Mcm4, Mcm7). The tree was generated by fast ML analysis using PHYML and rooted with archaeal MCMs. The numbers on each node are the bootstrap values and posterior probabilities from Bayesian analysis (values below $50 \%$ and 0.90 are not shown). Supporting values for each MCM paralogue and for the relationships between the eight MCM paralogues are highlighted in red.

Click here for file

[http://www.biomedcentral.com/content/supplementary/14712148-9-60-S1.pdf]

\section{Additional file 2}

Phylogenetic analysis of eukaryotic Mcm2-9 (part 2: Mcm5, Mcm6). The tree was generated by fast ML analysis using PHYML and rooted with archaeal MCMs. The numbers on each node are the bootstrap values and posterior probabilities from Bayesian analysis (values below $50 \%$ and 0.90 are not shown). Supporting values for each MCM paralogue and for the relationships between the eight MCM paralogues are highlighted in red.

Click here for file

[http://www.biomedcentral.com/content/supplementary/14712148-9-60-S2.pdf]

\section{Additional file 3}

Phylogenetic analysis of eukaryotic Mcm2-9 (part 3: Mcm3, Mcm2). The tree was generated by fast ML analysis using PHYML and rooted with archaeal MCMs. The numbers on each node are the bootstrap values and posterior probabilities from Bayesian analysis (values below $50 \%$ and 0.90 are not shown). Supporting values for each MCM paralogue and for the relationships between the eight MCM paralogues are highlighted in red. Highlighted in green is the supporting value for the origin of eukaryotic MCMs.

Click here for file

[http://www.biomedcentral.com/content/supplementary/14712148-9-60-S3.pdf]

\section{Additional file 4}

Phylogenetic analysis of eukaryotic Mcm2-9 (part 4: Mcm8, Mcm9, archaeal MCMs). The tree was generated by fast ML analysis using PHYML and rooted with archaeal MCMs. The numbers on each node are the bootstrap values and posterior probabilities from Bayesian analysis (values below $50 \%$ and 0.90 are not shown). Supporting values for each MCM paralogue and for the relationships between the eight MCM paralogues are highlighted in red. Highlighted in green is the supporting value for the origin of eukaryotic MCMs.

Click here for file

[http://www.biomedcentral.com/content/supplementary/1471-

2148-9-60-S4.pdf]

\section{Additional file 5}

Treefile for "Noah's Ark" dataset phylogenetic analysis of eukaryotic Mcm2-9. To attempt to further resolve the phylogeny of the Mcm2-9 proteins, specifically the branching relationships among the eight MCM paralogues, we conducted a reduced taxon phylogeny. In this analysis we used a limited sampling of eukaryotes from each major taxon (species indicated by asterisks in Figure 1) with the hope that the resulting reduction in tree space would enable us to resolve an improved phylogeny. The analysis did not show improved resolution among the terminal branches. The tree was calculated from an alignment of 120 sequences and 307 characters by fast $M L$ analysis using PHYML with 100 bootstrap replicates. The tree can be viewed using TREEVIEW.

Click here for file

[http://www.biomedcentral.com/content/supplementary/1471-

2148-9-60-S5.txt] 


\section{Additional file 6}

Eukaryotic genomes and predicted proteomes analysed in this study. Click here for file

[http://www.biomedcentral.com/content/supplementary/14712148-9-60-S6.doc]

\section{Additional file 7}

Treefile for phylogenetic analysis of eukaryotic Mcm2-9 using LG matrix. The tree was generated by fast ML analysis using PHYML with the LG matrix, with 100 bootstrap replicates. The tree can be viewed using TREEVIEW

Click here for file

[http://www.biomedcentral.com/content/supplementary/14712148-9-60-S7.txt]

\section{Acknowledgements}

We would like to thank Darren Soanes for specialist bioinformatics support. We would also like to thank Oslo Bioportal http://www.biopor tal.uio.no for computer resources and phylogenetic applications.

\section{References}

I. Sclafani RA, Holzen TM: Cell cycle regulation of DNA replication. Annu Rev Genet 2007, 4I:237-280.

2. Maine GT, Sinha P, Tye B-K: Mutants of S. cerevisiae defective in the maintenance of minichromosomes. Genetics 1984, 106:365-385.

3. Tye BK: MCM proteins in DNA replication. Annu Rev Biochem 1999, 68:649-686.

4. Chong JP, Thömmes $P$, Blow J]: The role of $M C M / P I$ proteins in the licensing of DNA replication. Trends Biochem Sci 1996 21:102-106.

5. Kearsey SE, Labib K: MCM proteins: evolution, properties, and role in DNA replication. Biochim Biophys Acta 1998 , 1398: 113-136

6. Forsburg SL: Eukaryotic MCM proteins: beyond replication initiation. Microbiol Mol Biol Rev 2004, 68: I09-I3 I.

7. Walter JC, Araki H: Activation of pre-replication complexes. In DNA Replication and Human Disease Edited by: DePamphilis ML. Cold Spring Harbor: Cold Spring Harbor Laboratory Press; 2006:89-104.

8. Moore $\mathrm{K}$, Aves SJ: $\mathrm{Mcm} \mathbf{I} \mathbf{O}$ and DNA replication in fission yeast. In The Eukaryotic Cell Cycle Edited by: Bryant JA, Francis D. Abingdon:Taylor and Francis; 2008:45-69.

9. Moyer SE, Lewis PW, Botchan MR: Isolation of the Cdc45/Mcm27/GINS (CMG) complex, a candidate for the eukaryotic DNA replication fork helicase. Proc Natl Acad Sci USA 2006, I 03:10236-1024|.

10. Pacek M, Tutter AV, Kubota Y, Takisawa H, Walter JC: Localization of MCM2-7, Cdc45, and GINS to the site of DNA unwinding during eukaryotic DNA replication. Mol Cell 2006, 2 I:58I-587.

II. Barry ER, Bell SD: DNA replication in the Archaea. Microbiol Mol Biol Rev 2006, 70:876-887.

12. Gozuacik D, Chami M, Lagorce D, Faivre J, Murakami Y, Poch O, Biermann E, Knippers R, Bréchot C, Paterlini-Bréchot P: Identification and functional characterization of a new member of the human Mcm protein family: hMcm8. Nucleic Acids Res 2003, 31:570-579.

13. Maiorano D, Cuvier O, Danis E, Méchali M: MCM8 is an MCM2-7related protein that functions as a DNA helicase during replication elongation and not initiation. Cell 2005, I 20:3 I 5-328.

14. Volkening M, Hoffmann I: Involvement of human MCM8 in prereplication complex assembly by recruiting hcdc6 to chromatin. Mol Cell Biol 2005, 25:1560-1568.

15. Kinoshita Y, Johnson EM, Gordon RE, Negri-Bell H, Evans MT, Coolbaugh J, Rosario-Peralta Y, Samet J, Slusser E, Birkenbach MP, Daniel DC: Colocalization of MCM8 and MCM7 with proteins involved in distinct aspects of DNA replication. Microsc Res Tech 2008, 71:288-297.
16. Matsubayashi H, Yamamoto MT: REC, a new member of the MCM-related protein family, is required for meiotic recombination in Drosophila. Genes Genet Syst 2003, 78:363-37I.

17. Blanton HL, Radford SJ, McMahan S, Kearney HM, Ibrahim JG, Sekelsky J: REC, Drosophila MCM8, drives formation of meiotic crossovers. PLoS Genetics 2005, I :e40.

18. Yoshida K: Identification of a novel cell-cycle-induced MCM family protein MCM9. Biochem Biophys Res Commun 2005, 331:669-674.

19. Lutzmann M, Maiorano D, Méchali M: Identification of full genes and proteins of MCM9, a novel, vertebrate-specific member of the MCM2-8 protein family. Gene 2005, 362:5I-56.

20. Shultz RW, Tatineni VM, Hanley-Bowdoin L, Thompson WF: Genome-wide analysis of the core DNA replication machinery in the higher plants Arabidopsis and rice. Plant Physiol 2007, I44:1697-1714.

21. Lyer LM, Aravind L: The evolutionary history of proteins involved in pre-replication complex assembly. In DNA Replication and Human Disease Edited by: DePamphilis ML. Cold Spring Harbor: Cold Spring Harbor Laboratory Press; 2006:75 I-757.

22. Passmore $S$, Elble $R$, Tye $B K$ : A protein involved in minichromosome maintenance in yeast binds a transcriptional enhancer conserved in eukaryotes. Genes Dev 1989, 3:921-935.

23. Christ C, Tye BK: Functional domains of the yeast transcription/replication factor MCMI. Genes Dev 1991, 5:75।-763.

24. Simpson AG, Roger AJ: The real 'kingdoms' of eukaryotes. Curr Biol 2004, I 4:R693-696.

25. DePamphilis ML: DNA Replication and Human Disease Cold Spring Harbor: Cold Spring Harbor Laboratory Press; 2006:313-34.

26. Adl SM, Simpson AG, Farmer MA, Andersen RA, Anderson OR, Barta JR, Bowser SS, Brugerolle G, Fensome RA, Frederica S, James TY, Karpov S, Kugrens P, Krug J, Lane CE, Lewis LA, Lodge J, Lynn DH, Mann DG, McCourt RM, Mendoza L, Moestrup O, Mozley-Standridge SE, Nerad TA, Shearer CA, Smirnov AV, Spiegel FW, Taylor MF: The new higher level classification of eukaryotes with emphasis on the taxonomy of protists. J Eukaryot Microbiol 2005 , 52:399-45I.

27. Rodríguez-Ezpeleta N, Brinkmann H, Burey SC, Roure B, Burger G, Löffelhardt W, Bohnert HJ, Philippe H, Lang BF: Monophyly of primary photosynthetic eukaryotes: green plants, red algae, and glaucophytes. Curr Biol 2005, I 5: I325-I330.

28. Rodríguez-Ezpeleta N, Brinkmann H, Burger G, Roger AJ, Gray MW, Philippe $\mathrm{H}$, Lang BF: Toward resolving the eukaryotic tree: the phylogenetic positions of jakobids and cercozoans. Curr Biol 2007, 17:1420-1425.

29. Sible JC, Erikson E, Hendrickson M, Maller JL, Gautier J: Developmental regulation of MCM replication factors in Xenopus laevis. Curr Biol 1998, 8:347-350.

30. Keeling PJ, Fast NM: Microsporidia: biology and evolution of highly reduced intracellular parasites. Annu Rev Microbiol 2002, 56:93-116.

31. Ohta N, Matsuzaki M, Misumi O, Miyagishima S-Y, Nozaki H, Tanaka K, Shin-I T, Kohara Y, Kuroiwa T: Complete sequence and analysis of the plastid genome of the unicellular red alga Cyanidioschyzon merolae. DNA Res 2003, 10:67-77.

32. Maiorano $D$, Lutzmann $M$, Méchali $M$ : MCM proteins and DNA replication. Curr Opin Cell Biol 2006, 18:130-136.

33. Guindon S, Gascuel O: A simple, fast, and accurate algorithm to estimate large phylogenies by maximum likelihood. Syst Biol 2003, 52:696-704.

34. Ronquist F, Huelsenbeck JP: MrBayes 3: Bayesian phylogenetic inference under mixed models. Bioinformatics 2003, I9:1572-1574.

35. Grabowski B, Kelman Z: Archaeal DNA replication: eukaryal proteins in a bacterial context. Annu Rev Microbiol 2003, 57:487-5 I6.

36. Burki F, Shalchian-Tabrizi K, Pawlowski ]: Phylogenomics reveals a new 'megagroup' including most photosynthetic eukaryotes. Biology letters 2008, 4:366-369.

37. Fitzpatrick D, Logue M, Stajich J, Butler G: A fungal phylogeny based on 42 complete genomes derived from supertree and combined gene analysis. BMC Evol Biol 2006, 6:99.

38. James TY, Kauff F, Schoch CL, Matheny PB, Hofstetter V, Cox C] Celio G, Gueidan C, Fraker E, Miadlikowska J, Lumbsch HT, Rauhut A, Reeb V, Arnold AE, Amtoft A, Stajich JE, Hosaka K, Sung G-H, Johnson D, O/'Rourke B, Crockett M, Binder M, Curtis JM, Slot JC, 
Wang Z, Wilson AW, Schüßler A, Longcore JE, O/'Donnell K, Mozley-Standridge S, Porter D, Letcher PM, Powell MJ, Taylor JW, White MM, Griffith GW, Davies DR, Humber RA, Morton JB, Sugiyama J, Rossman AY, Rogers JD, Pfister DH, Hewitt D, Hansen K, Hambleton S, Shoemaker RA, Kohlmeyer J, Volkmann-Kohlmeyer B, Spotts RA, Serdani M, Crous PW, Hughes KW, Matsuura K, Langer E, Langer G, Untereiner WA, Lücking R, Büdel B, Geiser DM, Aptroot A, Diederich P, Schmitt I, Schultz M, Yahr R, Hibbett DS, Lutzoni F, McLaughlin DJ, Spatafora JW, Vilgalys R: Reconstructing the early evolution of Fungi using a six-gene phylogeny. Nature 2006, 443:818-822.

39. Embley TM, Martin W: Eukaryotic evolution, changes and challenges. Nature 2006, 440:623-630.

40. Andersson JO, Sarchfield SW, Roger AJ: Gene transfers from nanoarchaeota to an ancestor of diplomonads and parabasalids. Mol Biol Evol 2005, 22:85-90.

4I. Cavalier-Smith T: The excavate protozoan phyla Metamonada Grassé emend. (Anaeromonadea, Parabasalia, Carpediemonas, Eopharyngia) and Loukozoa emend. (Jakobea, Malawimonas): their evolutionary affinities and new higher taxa. Int J Syst Evol Microbiol 2003, 53:174I-1758.

42. Ishimi Y: A DNA helicase activity is associated with an MCM4, -6, and -7 protein complex. I Biol Chem 1997, 272:24508-245 I3.

43. Crevel G, Hashimoto R, Vass S, Sherkow J, Yamaguchi M, Heck MM, Cotterill S: Differential requirements for MCM proteins in DNA replication in Drosophila S2 cells. PLoS ONE 2007, 2:e833.

44. Lutzmann M, Méchali M: MCM9 binds CdtI and is required for the assembly of prereplication complexes. Mol Cell 2008, 31:190-200.

45. Ramesh MA, Malik SB, Logsdon JM Jr: A phylogenomic inventory of meiotic genes; evidence for sex in Giardia and an early eukaryotic origin of meiosis. Curr Biol 2005, 15: |85-19|.

46. Birky CW Jr: Sex: is Giardia doing it in the dark? Curr Biol 2005, I 5:R56-58

47. Wohlschlegel JA, Dhar SK, Prokhorova TA, Dutta A, Walter JC: Xenopus Mcm 10 binds to origins of DNA replication after Mcm2-7 and stimulates origin binding of Cdc45. Mol Cell 2002, 9:233-240.

48. Gregan J, Lindner K, Brimage L, Franklin R, Namdar M, Hart EA, Aves SJ, Kearsey SE: Fission yeast $\mathrm{Cdc} 23 / \mathrm{Mcm} I 0$ functions after prereplicative complex formation to promote $\mathrm{Cdc45}$ chromatin binding. Mol Biol Cell 2003, I 4:3876-3887.

49. Sawyer SL, Cheng IH, Chai W, Tye BK: Mcm IO and Cdc45 cooperate in origin activation in Saccharomyces cerevisiae. J Mol Biol 2004, 340:195-202.

50. Ricke RM, Bielinsky AK: Mcm I 0 regulates the stability and chromatin association of DNA polymerase-alpha. Mol Cell 2004, 16:173-185.

5I. Gambus A, Jones RC, Sanchez-Diaz A, Kanemaki M, van Deursen F, Edmondson RD, Labib K: GINS maintains association of Cdc45 with MCM in replisome progression complexes at eukaryotic DNA replication forks. Nat Cell Biol 2006, 8:358-366.

52. Yang X, Gregan J, Lindner K, Young H, Kearsey SE: Nuclear distribution and chromatin association of DNA polymerase alphaprimase is affected by TEV protease cleavage of Cdc23 (Mcm I 0) in fission yeast. BMC Mol Biol 2005, 6:13.

53. Finn RD, Mistry J, Schuster-Böckler B, Griffiths-Jones S, Hollich V, Lassmann T, Moxon S, Marshall M, Khanna A, Durbin R, Eddy SR, Sonnhammer EL, Bateman A: Pfam: clans, web tools and services. Nucleic Acids Res 2006, 34:D247-25I.

54. Edgar RC: MUSCLE: multiple sequence alignment with high accuracy and high throughput. Nucl Acids Res 2004 32: $1792-1797$.

55. Galtier N, Gouy M, Gautier C: SEAVIEW and PHYLO WIN: two graphic tools for sequence alignment and molecular phylogeny. Comput Appl Biosci 1996, 1 2:543-548.

56. Keane TM, Creevey CJ, Pentony MM, Naughton TJ, Mclnerney JO: Assessment of methods for amino acid matrix selection and their use on empirical data shows that ad hoc assumptions for choice of matrix are not justified. BMC Evol Biol 2006, 6:29.

57. Le SQ, Gascuel O: An improved general amino acid replacement matrix. Mol Biol Evol 2008, 25: | 307-| 320.

58. Page RD: TreeView: an application to display phylogenetic trees on personal computers. Comput Appl Biosci 1996, 12:357-358
Publish with Biomed Central and every scientist can read your work free of charge

"BioMed Central will be the most significant development for disseminating the results of biomedical research in our lifetime. "

Sir Paul Nurse, Cancer Research UK

Your research papers will be:

- available free of charge to the entire biomedical community

- peer reviewed and published immediately upon acceptance

- cited in PubMed and archived on PubMed Central

- yours - you keep the copyright 